\title{
THE ETHNOGRAPHICAL ESSAY: \\ Cine Club in the Refugee Camp \\ - THE STORY OF A DOUBLE EMPOWERMENT
}

\section{Izabela Wagner*}

\begin{abstract}
The article is an ethnographic essay, which is based on a long-lasting fieldwork conducted in an Italian refugee center. The first part contains basic information on the research project, as well as the presentation of the phenomenon - empowerment - which is the axis of this text. The second part has an innovative form: on the canvas of films watched with refugees, I am conducting the analysis of problems raised by participants.
\end{abstract}

Keywords: refugees, camp, empowerment, ethnography, films

Creating the English-language version of the journal "Zoon Politikon" is financed under contract No. 724/P-DUN/2018 from the funds allocated by the Minister of Science and Higher Education for dissemination of science.

This article is partially based on the research conducted under the frame of the grant OPUS 13, $2017-\mathrm{HOPE}$ [2017/25/B/HS6/01725] financed by Polish National Science Centre.

While the ethnographical essay is not perceived today as a strict "scientific" text, it enables larger public to learn directly from the researcher and not via a journalistic account. This article is an attempt to combine two approaches and could be read in a two different ways:

1) entirely - as a typical sociological paper;

2) partially - focusing on the cine-club activity (parts $1 A$ and 6 ) [smaller font].

*Izabela Wagner, Ph.D., professor of Collegium Civitas, Poland \& Associated Researcher DynamE - Dynamiques Européennes L'UMR7367 - CNRS - Université de Strasbourg \& Fellow Institut Convergence Migration Paris, France. e-mail: izabela.wagner@civitas.edu.pl | ORCID: https://orcid.org/0000-0002-6521-0477 
Pour nos amis de "campo"1

\section{Introduction}

\section{A. Fieldnotes [adapted for the article]: Introduction to my "ethnographical

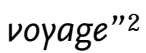

Winter, Tuesday afternoon. I am arriving at the camp in my car. The rain is so strong that I have trouble to cross 10 meters from the parking to the main door. Abraham ${ }^{3}$ is waiting on me in the entrance - he opens the door and says with a smile as usual: "How are you, I hope you are doing well?".

He is helping me with my heavy bags and we are going downstairs where two persons are moving tables and chairs, preparing all as usual for our cine-club meeting. Abraham is calling other participants in French mixed with Fulani.

It is very cold, wet and dark in the large room. A basement without hitting is a nice place in the summer when the temperatures cross 30C, but in winter the humidity makes this place simply insane. I keep all sweaters and my big coat which remembers strong Polish winters, I move the small electric radiator for having at least some dry and hot air. I am connecting a projector with a computer. When everything is fixed we begin.

- Bonjour! Comment ça-va? [I am asking in French - this is a francophone group on Tuesday]

\footnotetext{
'In French - "For our friends from the camp". I dedicate this paper in French - our language of communication. The last word is in Italian, while this is how inhabitants of camp call it. I am grateful to Sidi, Mamadou, Kindy and many others who helped me to understand their worlds.

Nos (in French "Our") in the dedication comports 2 persons - my life partner and myself, while we worked together in this project. He wished to not co-sign the paper even if his contribution is significant. Respecting his decision, I would like to thank Philippe Saffray for his huge involvement in the voluntary work and in my research project (for which he was never remunerated neither co-authored the papers).

${ }^{2}$ I wish to thank anonymous reviewers for their suggestions. One of them employed an adequate term which I am citing "the ethnographical voyage" - I am grateful for this expression.
}

${ }_{3}$ All names were changed. 
- Ça va comme-d, comme-ça! They respond - which means that this is not everything OK. The most important - the news about their "commission" are not announced yet...they are still waiting (since months now).

They look tired and are frozen. Some have sweaters, some only a cotton T-shirts and tiny jackets. One person comes with a hat. All, except one who has baskets, are in flippers... four wear the big wool socks [which my mum bought on the market from Ukrainians ('they have excellent winter product') and sent me in the packet from Poland "for the boys"]. Others have bare feet and I wonder how they can bear the cold that penetrates the bones... "We are used to it..." responds Boubakar. I know that during the weather like today (which is regular wintertime in Southern Italy) they are lying all day in their bed, while outside is too chilly. The meals and our meetings are the only moments when they are out from their icy and humid rooms. Despite the pain caused by low temperature, they made the efforts and came for our workshop. They are frozen and cough. One of them, with a tired smile, asks: "What are we watching today?"

As usual, I propose 3 movies - they are choosing a comedy without a quarrel. During over 2 hours we will have the illusion that we are friends who are simply watching a movie. The illusion concerns not our relationship - with time we would become friends, but everything around us is not as it should be. We are not in the cinema hall, or at home, drinking tea or coffee in the warm space. We did not meet in our free time to watch a funny movie.

We pretended that this frame is an ordinary setting. But it does not. This is an illusion of an ordinary situation. This is not, as it should be.

All around us is not as it should be. For newcomers to Europe, this is a dark time. Our doors are closed and the walls between "them" and "us" are growing (Bauman 2015; Héran 2019). Even the actions of volunteers are sabotaged and criminalized by state institutions (see the situation in Paris and Calais for example). How exiled extraEuropean people can meet us - Europeans if they are closed in the centers of retention/ camps/ghetto/ bidon-villes? How we - Europeans - can be tolerant and open-minded, if we are growing in the fear of others and we are living in the states, in which security policy prevails over the value of hosting the "other"? 
How long again researchers will keep explaining that "old" Europe needs newcomers and the earth history is a long story of permanent migrations? The voices of researchers (historians, sociologists, anthropologists, demographers, economists) are muted - this is our contextual dis-empowerment.

\section{B. Terms, definitions and limits}

The term empowerment is commonly defined as "authority or power given to someone to do something" (Lexico 2019). Dictionary definitions often include the term control in reference to one's own life - "to give someone more control over their life or more power to do something" (Macmillan Dictionary 2019) ${ }^{4}$. This article is concerned with regaining, or simply making it possible to regain, a small degree of control over one's own life. In the case of the participants of the study the "refugees" (more precisely - asylum seekers in Europe), a "small

\footnotetext{
4 There is a consistent sociological reflection about empowerment. This is a concept started to be popular with Foucault (1980) then used in mainly in sociology of work, pedagogy (Freire 1970; Archibald, Wilson 2011); social work (Solmon 1976), social movements (Comparative Perspectives on Social Movements. Political Opportunities, Mobilizing Structures, and Cultural Framings 1996) and in feminist studies (Deveaux 1994). For the exhaustive view of the concept of empowerment in sociology see Bartunek, Spreitzer (2006). The concept is also employed by psychologists (Zimmerman 2000), who developed specific tools to investigate empowerment - this approach is also used in the management and leadership studies (in the field of motivation).

In the area of refugees studies several publications are using "empowerment approach" (Scheibelhofer 2019) however there are another context and methodology, which are employed in this article. In scientific literature, the empowerment approach is most often related with macro and mezzo dimensions. The micro dimension is almost always present in the publications by practitioners working with refugees, while the empowerment is a very important political concept. One of the examples is to give the voice to exiled people by the organizations in a direct contact with them (UNHCR 2014). EU Commission, supports several initiatives using the term empowerment: Migrempower (http://www.migrempower.eu/) is the most important project that should frame the work of volunteers active under various ONGs and others organizations. Similar project, the Center for Refugees Empowerment, was created in 2018 bringing practitioners to work together on the integration of "refugees" in Austria (https://www.uia-initiative.eu/en/uia-cities/vienna). This project put together the activists, volunteers, civil society initiatives and refugees. This is a new and experimental initiative supported by Austrian government. Interesting project about empowerment and knowledge sharing in Germany - https://www.kiwit.org/media/material-downloads/publication_teachers_for_life.pdf. All those projects concerns applied works.
} 
degree" is more applicable, as the use of the term "regaining control of one's own life" is inadequate.

This article presents the process of regaining dignity and attaining a certain kind of empowerment - the ability to communicate, express opinions, feelings and exchange information with Europeans who are not part of the administrative system controlling the lives of asylum seekers (during their stay in the "refugee camps").

The term "empowerment" is preceded by the adjective "double", as strengthening or attributing a certain degree of agency ${ }^{5}$ to people who are unable to influence their own actions concerns both parties involved in encounters where "empowerment" occurs. Thus, "double" refers to the group of asylum seekers in attendance and to the researcher leading the classes. The article focuses primarily on a group of asylum seekers engaged in the process of regaining dignity ${ }^{6}$ and partial control over their own lives through a series of activities called "cine-club". It is complemented by a shift in the sensation of empowerment and meaning of the work performed by the leader of these meetings.

Researchers studying the world of "refugees" are frequently reporting the difficulty to find an adequate definition of the key terms in their fields. The reality is much more complex than the conceptual constructs, that we (researchers) are used to employ; frequently the terminology is imported from legal texts and juristic language related to the immigration law, economy (institution for employment) and media. How to providea credible analysis of the complex situations (the life in the camp) applying the theoretical conceptual framework created for use other than understanding a social reality? In other words, the dynamic of in vivo situations escapes the static concepts. Two key categories of this article (refugees and camp) are perfect examples of above-mentioned hiatus.

5 About agency in the field of sociology, see: Iwińska 2008.

${ }^{6}$ About dignity among refugees see for example Chandrashekhar Oka (2014). 
Michel Agier, French anthropologist remarks that "[t]he situations of people on the move is often very diverse, or even opposed: on the one hand, refugees falling under the right of asylum and more generally »human rights « protection and, on the other hand, they are so-called »economic« migrants, of which we suppose free choice as the primary data and labor power as their only resource. The links between these two institutional categories are established in fact by the economic uses of the different official statuses of foreigners, as long as they correspond to precarious status related to the work. The same person can thus find themselves in two situations that they did not want: to be both, an asylum seeker awaiting an acceptance that does not arrive and an informal or illegal worker at a salary lower than that of locals"7 (Agier 2014, p. 284).

Defining refugees camp is also not an easy task. French sociologist Marc Bernardot (2007) is speaking about the exceptional plasticity as a major feature of the camps. Based on my experience, I believe that the spaces of refugees retention in massive closed camps correspond perfectly with the definition of a concentration camp; that is, as the preemptive communal detention of innocent civilians (Pitzer 2017, p. 6-8).

Michel Agier, in the book that cumulates the case-studies from the different continents, underlines camp's hybridity: “Hybrid forms, heterogeneous recent and for some still experimental, these are places for which the names of prison, ghetto or shanty town would sometimes

\footnotetext{
7 “Les situations de personnes en déplacement souvent distinguées, voir opposées: d'un côté, les refugiésrelevant du droit d'asile et plus generallement de »droit de l'homme« et, d'un autre côté, les migrants dits »économiques«, dont on suppose le libre-choix comme donnée première et la force de travail comme seule ressource. Le liens entre ces deux catégories institutionnelles est établi de fait par les usages économiques des différents statuts officiels d'étrangers, dès lors qu'ils corresponent à des status precaires dans le travail. Une même personne peut ainsi se trouver dans deux situations qu'elle n'a pas désirées: être la fois demandeur d'asile en attente d'une acceptation qui n'arrive pas et travailleur informel ou illégal au salaire inférieur à celui des locaux" (Agier 2014, p. 284).
} 
be better adapted than those of camps or encampment"8 (Agier 2014, p. 283).

Taking into account this hybridity, my text comports detailed information, which helps to understand the particular situation of persons who are the participants of this study, rather than applies terms borrowed from other studies. The form of an essay allows such escape from the classical framework inscribed to the scholar paper.

\section{The context of the study}

This article is based on ethnographic research conducted between 2017 and 2018 in a refugee camp in southern Italy. In 2015, in response to the growing number of asylum seekers and in response to the so-called "refugee crisis" - a media campaign alarming the European public about theinflux of asylum seekers from Asia and Africa - the Italian authorities changed the law in the camps and allowed social cooperatives (also NGOs) to open reception centers for asylum seekers. Reception centers are places of forced residence where asylum seekers in the $\mathrm{EU}^{9}$ are retained for the duration of theadministrative process for their requests to be assessed.

In Italy, the waiting period for the decision is becoming increasingly longer, ranging from 18 months to more than 2 years. During this time, residents of the camp (officially called the first reception center) should be provided with basic necessities: food, a place to sleep, personal hygiene facilities, adequate clothing and appropriate medical care. The camps are financed (by the EU, via state institutions) depending on the

8 "De formes hybrides, hétérogènes récentes et pour certaines encore experimentales, ce sont des lieux pour lesquelles les noms de prison, de ghetto ou de bidonville seraient parfois mieux adaptés qie ceix de camps ou campements" (Agier 2014, p. 283).

9 The legal issues related to the process of granting the refugee status (political or humanitarian) and the various categories of persons who have migrated to Europe from Asia and Africa in a way that the EU considers "illegal" shall not be elaborated upon. 
number of people in the camp (the central authorities allocated 35 Euros for every asylum seeker per day ${ }^{10}$ ).

The institutions responsible for providing for the basic needs of the residents did not cover them beyond the material aspects; the exception was the language course in Italian (which was not well received by all camp residents, since Italy was not the place where the majority of the residents planned to live; committing to the course was motivated by the desire to obtain documents, as language familiarity was an important factor in being granted permits, as well as in getting a job).

Italian language classes created a unique context, where refugees met Europeans who are not directly involved in the process of obtaining a residence permit. The residents of the camp may have left the center, but in reality, they lived in isolation and had no regular opportunity of getting acquainted with the Europeans, their lives or the specific nature of the local culture. Their presence in the town, with the camp being situated near the center, did not mean that they could speak with each other or establish permanent relations.

At the same time, it was widely expected that refugees would adapt to our European way of life and to our "values" as soon as possible (judging from the interviews with residents and numerous media articles on the current issue). It would appear that the waiting period for one of the possible categories of residence in the EU should be used to acquire certain information that would enable them to "adapt".

This is what the institutions dealing with the "absorption" of new Israelis have done and are doing. They teach the basic knowledge necessary for functioning in the new society; new citizens of Germany are integrated in a similar way - along with the language, they acquire knowledge about life in their new country. In Italy, as in France, such a transfer of information is not part of what is considered "basic care for refugees". The two-year period and the enormous amount of free

${ }^{10}$ At the time the study was conducted. 
time (without the possibility of gainful employment) are not managed in any way. Months go by with no contact nor conversations between the local and migrant population. How are the asylum seekers from Africa and Asia supposed to find out how we, Europeans, live?

"Introduction to Europe" is an idea to hold meetings - a type of conversation classes - to fill this gap and to exchange knowledge concerning culture, customs and values that we define as "European" and those that the asylum seekers consider being their own. However, what are the methods of organizing such activities in isolation and in relation to a multinational, multilingual population which is partially not able to read (illiteracy is common) without a guide focusing on life in European societies? In response to these limitations, I decided to use videos as a basis for discussion on selected elements of European culture and the cultures represented by the participants in the activities called the "Cine-Club". The article discusses the history of the project, the asylum seekers' camp context, and analyses the selected topics of the workshops. The conclusion will attempt to summarize the changes that took place as a result of our meetings and subsequent discussions (between workshop participants and the leader).

2. Methodology: conducting field research in the camp

The activities aimed at creating a space for discussion on the cultures of asylum seekers and hosts and were proposed as a voluntary activity. After several months of waiting for the necessary permits and negotiations with the administration of the center, the first working meeting with the residents of the camp took place. With another volunteer (my life partner) in charge of the music workshop, we presented our projects during the lunch - at the canteen, where over 50 persons ate a modest meal in the plastic boxes prepared by a catering 
firm. In order to follow the proposed activities, they should inscribe their name on the list that was attached to the door of the main office.

At the time, the institution was responsible for 110 persons, mainly men from Africa (majority) and Asia (minority). The vast majority of the asylum seekers went to Italy via the so-called Mediterranean route using ribs, which were later abandoned on the open sea, along with the engine. Most of them lived through traumatic experiences. The camp nurse told me that all of them should go to therapy, but there are no funds and communication is limited (they do not speak Italian). This information is confirmed by the data provided by physicians working with the asylum seekers (Nosè et al. 2017; Crepet et al. 2017). For this reason, I have decided that traumatic and difficult issues will constitute a minuscule part of our conversations and that the movies will consist mostly of comedies. The movies were humorous, and concerned the issues hope and love - I did not have to restrict the movies according to age.

The adult camp was mainly inhabited by young men (20 to 35 years of age, mostly) speaking African and Asian languages (about twenty Bengalese men) and some of them were fluent in French or English (several people knew both). Most of them attended the Italian language course, which started in late autumn (over hour-long classes, twice a week, in groups of more than 15 people ${ }^{11}$ ). For structural reasons (daytime presence at the center) the cine-club became a Frenchspeaking workshop after a few months. The regular group of participants did not exceed 10 people, but very often the classes were attended by additional people (there were over 50 persons watching movies from time to time with us).

$"$ Refugees complained about frequent breaks (vacation and holidays), which caused their low involvement. Not everyone attended the classes. Some had a plan was to leave Italy immediately after receiving the relevant documents. 
From the core group (10 persons attended the meetings during the whole year'2) 7 lived in the capital cities before leaving their countries. Four were born in the countryside, then moved to the city (some with parents). Only four had a high-school certificate, one finished the first year of the university (languages) and one had the technical diploma (3 years post-high-school). Except for two persons who left their countries as students, other persons had various jobs. Three were car's mechanics, one had a shop with CDS and video games and three worked at an oil station and in the sell of all kind of goods (form alimentary products to the gold). Four persons worked at the restaurant however not in their country, but in the "travel" - in Algeria. Two persons had the part of their careers in the military institutions.

Using European categories, we could say that they were mainly middle-class persons, but this is exactly an example of our - researchers ethnocentrism, while our class categorization was constructed based on European industrial societies. How to apply sociologically adequate categorization for this diverse population originated from a different context (Africa, Asia)? The wish to depict the group with our western categories is also an element of our post-colonial approach, which replace the lack of knowledge about African populations by our western habits.

For Western Africa (the geographical area from which the majority of the participants of workshops were originated) we should say: there were Peuls (Fulani), Bambara, Wolof, Soussou Djoula, Malinke and Mandingo and some persons of mixed from those mentioned origins. Except one, all workshop participants (originated from former French territories, in which schooling is conducted in the French language) had a very good command of French and only 2 spoke rudimentary English. One person never attended school, two had difficulties with reading and

${ }_{12}$ We should recall the regular decrease of the number of inhabitants from 110 to less than 40 at the end of the school year. 
four were active readers. Four persons were fathers and two of them were married (the family reminded in Africa).

The ethnicity, age and language skills, as well as the time spent in the camp, were important factors in our group positioning. There was significant competition between three persons who were leaders and managed their community members - sort of chiefs and guides. One person played the role of religious authority and organized a series of prayers. Among the core group, all persons were Muslim (at various involvement in the practices as it could be observable from moderate respect of basic rules to the persons who consumed alcohol and did not respect the Ramadan) ${ }^{13}$.

If in this article participants to the workshop could appear as the homogeneous group, this is because of the context of our meetings, during which they created a team - they expressed similar opinions and had similar reactions to the projected movies. Three persons (better schooled and reading books) dominated discussions on the beginning, but with time, those who attended the workshops regularly and kept silence during first meetings took progressively part in our exchanges. The main features that imposed this similarity were the context of being isolated in this place - the campo. Using Hughesian master status concept - Hughes 1945 - we could say that their master status was their situation of the inhabitant of the camp.

From the very first meeting, one could see that the atmosphere in the camp was dominated by the conflict between the administration and asylum seekers. As the volunteers were introduced to the camp inhabitants by the administration and the activities had to be accepted by the authorities, the volunteers were seen as part of the administration. Due to this relationship, the asylum seekers were initially skeptical towards the volunteers. The instructors were seen as spies, and have to prove that they are not informants. Limitation of trust

\footnotetext{
13 The majority of the camp inhabitants were Muslim and there were a dozen of Christian.
} 
and common suspicion determined the quality of the relationships and therefore of the activities.

Due to this particular situation, as well as the unique possibility of staying in an environment difficult to access, characterized by features typical for total institutions, I decided to use the data collection methods used in the classical ethnographic field research. My fieldwork specificity could be compared to the fieldwork conducted in the total institutions (Goffman 1961) such as jails or military complexes. I drafted a research project and informed the group of participants that I considered "sensitive" - the asylum seekers. The administration of the camp was not informed about my work, but they knew that I was interested in the sociology of migration ${ }^{14}$.

I told the participants I was a sociologist specializing in migration and that I was writing a book about migration processes. I did not mention the exact topic of my research, but they expressed their consent and enthusiasm for the opportunity to participate in my work. They wanted to share their perspectives on life in the camp and Europe. I was and remained "their voice" which is typical in ethnographic research on disadvantaged populations (Liebow 1995; Duneier 1999; Harper 1982; Powdermaker 1967).

\section{Unusual State of Art}

If this methodological approach is known in sociological literature, it is impossible to provide a classical state of art related to the refugees camp based on the ethnographical long-lasting studies. Nevertheless, there are some research on the refugees camp. In this section, I will mainly focus on French-language literature.

\footnotetext{
14 Since the situation has not been clarified, it can be assumed that for some of the participants (the dominant group) I conducted an undercover study. After an event which revealed my research, I was banned from entering the center (unofficially). The project includes the study of other groups (local population and administration) but in this paper I am only focusing on the workshop activity.
} 
One of the most important work was published under the direction of anthropologist and expert in the refugees' camps - Michel Agier. This work includes the case studies from the whole world and is classified by topics: law, history (Abou-Zaki 2014), politics (Lecadet 2014; Bernardot 2014), economy (J ansen 2014). This book reflects the state of art in refugees studies, where the majority of studies could be classified into similar categories. Usually, authors are adopting the institutional, macro and mezzo points of view. Rarely micro. There are two major reasons for this absence.

First is the difficult access to the camp. If ONHCR camps are more accessible than the European center of retention and centers of reception, usually closed to the researchers and journalist ${ }^{15}$. There are some texts written by volunteers and therapist working mainly with children and in the countries with open-door policy toward exiled people (Austria, Finland). In these areas (minor-aged without parents refugees) seems to be more accessible to researchers (Akthar, Lovell 2019).

The situation when a researcher can enter inside the camp in Italy or France is extremely rare (see the case of Lampedusa, Denaro 2014; Tassin 2014). If some studies are conducted there - this is undercover. The "undercover" methodology influences not only the process of gathering the data but also their nature (any possibility to get access to another category of participants) as well as the final analysis. This is the reason for the absence of the administration and technical employees point of view (obtained usually in the interviews) in such studies.

Actually, the professionals working in those places have restricted possibility of expression and studies conducted in such places are controlled by the highest authorities. In Italy, volunteers also can rarely enter into those closed spaces, except for the language teachers (in the

15 Only works under cover are conducted - the rare and well known book by (Gatti 2007). In France, in 2019 volunteers and activists asked parliamentarians to visit those places (to check if Human Rights are respected) but even them had difficulties to enter in. 
places in which such lessons are aocepted). Others activities like sport and cultural animations most often take place outside the camps. In the spaces, which are called "jungle" - overpopulated camps without supervision, where lives the clandestine exiled groups, the humanitarian organizations provide the help (Calais "Jungle" is the most known example).

Medecins sans Frontieres and Medecin du Monde ${ }^{16}$ aport medical support, numerous NGO - vital basic care. Sometimes groups of volunteers are proposing some additional activities like sport, yoga even the art therapy (Godin et al. 2017), aiming the improvement of the health (including mental health) of exiled persons. While we can read some journalistic accounts about those activities, there are still only a few scientific texts published ${ }^{17}$. Although the access to the camp is very difficult, the ethnographical long-lasting projects are extremely rare, which signify that the direct contact between the researcher and the refugees (living in the camps) is strongly limited ${ }^{18}$.

The second factor which contributes to the absence of the text similar to this article is ethnocentrism. The camps in Europe and how the reception of the exiled people is conducted in EU states - this issue is studied from outside - from our European perspective. We - European researchers are writing to other European researchers about the problems which are interesting to us - European researchers. We are mainly publishing about our problems while conducting the study, macro and mezzo framework, categorizations, historical and political dynamics, law, regulations and procedures, health, public opinion and media, ethics (Halilovich 2013) as well the meta-articles (articles about the publications on refugees).

\footnotetext{
${ }^{16}$ Two main French charity organizations - the frame for the medical help.

17 The most often we can find the studies analyzing such topics as the health or the mental health of the refugees (Cernovsky 1988; Brown, Schale, Nilsson 2010; Crepet et al. 2017; Centre Primo Levi 2018).

18 This is probably the most often researchers (even those who are mentioning the field study and ethnography) are working based on the interviews with the volunteers.
} 
What is missing in those numerous accounts is the perspective of refugees (micro and/ or biographical approach). There are rare books and some texts inspired or written by them (UNHCR 2014; EdoguéNtang 2014; Godin et al. 2017). They are usually focused on the reasons for leaving their home, and principally on the journey. The traumatic experience of Libyan concentration camps and deadly cross of the Mediterranean Sea are the principal topics of published books (Kouamé 2018; Orland 2018; Kaba 2019). The account which includes the camp's life by Fabrizio Gatti (2007) an Italian investigation journalist working undercover and playing the role of a refugee, still is the exceptional sources of data for researchers, who have any access to the field.

Another exceptional case concerns the research in cover conducted in the agromafia sector by Marco Omizzolo (Omizzolo 2016 and Omizzolo, Fanissa 2019; see also exceptional movie - Harvest, 2017 with the participation of Marco Omizzolo).

To sum up, the majority of literature about the refugees is mainly about us facing them - rarely about the refugees themselves. According to my best knowledge, no interactional story, which would take place in the adult camp has been told up until now.

In those circumstances (quasi-absent focused state of art), this study belongs to the specific category - concerning a unique experience and an original analysis of the long-lasting relationship between the inhabitants of the camp and a researcher. This relationship was built in the frame of the regular meetings around the movies projections and the most importantly - the long discussions.

\section{Positionality}

The activities, which constituted the basis for data collection, took place twice a week. After watching a movie (usually in French, but also in English, which I translated into French, and in Italian, also translated 
into French), a discussion followed. My questions were always aimed at the interpretation of the movie, mainly in the cultural context. During the initial meetings, the discussion was mainly focused on gaining the trust of the attendees. Also, building a suitable space in which the balance between European and African cultures could be maintained was important ${ }^{19}$.

From the very first meeting, I attempted to demonstrate that there is no common European culture and wanted to find shared ideas between us. There has been a gradual reduction in the distance imposed by our different statuses: a volunteeringlocal and an isolated group from a semiclosed institution; an academic and not used to the university context listeners; a lecturer and her students; a person with a legal status and means of independent living and a group dependent on state support and managed by the administration.

An additional element which helped reduce that distance was the fact that I understood what immigrants go through. I have in their situation twice: at the beginning of my adult life when, after graduating, I moved to France and for 18 years of my life I was referred to as "that Pole" despite being a French citizen, marrying a French citizen and starting a family in that country, as well as continuing my education.

The experience of exclusion, certainly different from that experienced by Africans in Europe, made it possible for me to understand the position of a person who was rejected or simply not treated as their own.

The second experience of being the "Other" was recent - for over a year, I was a resident of Italy and the same town, not fluent in Italian and only learning about local customs and culture. We shared our observations typical of the "newcomers", which meant that we belonged to the same category - the new residents of Italy.

\footnotetext{
19 I projected to watch African movies. But it was impossible; firstly because the Internet connexion was poor and secondly, the movies I have on DVD's were militant films with sharp pessimistic content. We decided to skip this idea.
} 
It is also worth mentioning the important issue of the gender and ethnicity difference - a white woman conducting classes with darkskinned men. This aspect could be an issue if it were not for the presence of my life partner in the camp, who conducted music workshop. Our common involvement deprived us of any problems of masculine and feminine nature - we became friends, after some time (the participants sometimes visited us at home). By reducing the distance between us, in the span of a few months, we managed to gain the trust of the asylum seekers and establish friendships with some of them, which were maintained outside the activities and even after their departure from the camp. It was this type of a close and friendly relationship that made it possible to explore the issue of "cultural differences", "learning about European values" and ultimately change how Europeans are perceived. Discussing the movies and life situations similar to those presented on the screen proved to be a great base for mutual understanding. This positive process took place, however, under unfavorable conditions.

\section{Current research context}

From the very beginning, we had to overcome external obstacles which discouraged volunteers and made them cease coming to the meetings. The TV set on which the movies were displayed could not be connected to the computer - I waited 2 months for the administration to buy the appropriate cable despite the low cost (EUR 20) and trouble-free availability. The way out of this situation was to watch movies on a computer with a large monitor, belonging to a person from the administration - this solution lasted only for five meetings. After buying the cable myself, it turned out that it was impossible to turn the TV on and organize the meetings because someone had "stolen" the remote, the punishment for which was - suspending the activities. One 
of the peoplein charge of theadministration preemptively assumed that the remote was "appropriated" by one of the asylum seekers: "after all, they have to learn they can't get away with that - Europe is no place for thieves!" I protested the unjustified accusations and unfair punishment. Nonetheless, our workshops were canceled - there was no meeting at all because I received a blunt suggestion to leave.

The remote control was found on the same day - someone simply borrowed it to turn on their TV in another room. When the meetings started taking place regularly for more than a month without needless interruption, it suddenly became clear that reorganization would be imminent. Our activities were moved to a damp, cold and unheated basement because the previous place was repurposed as an office extension. The room smelled of mold, and the damp, green plug did not meet any safety standards and posed a risk of electric shock. Because our descent "into the underground" took place in the winter, participants came wearing flip-flops without socks (the most often they did not have them), and all sweaters they had; sometimes they also wore hats and scarves. I did not take my coat off either, and I brought extra clothes.

This way, I discovered that the center was unheated. Not only "our basement" but also the rooms. For switching on heaters, which the asylum seekers bought themselves at a supermarket (priced around 20$30 \mathrm{E}$ ), penalties were applied (due to high costs of electricity, of course). Three hours of meetings made me so cold that it was difficult for me to get warm, even several hours after returning to warm conditions. The residents of the camp did not get such an opportunity, because they had to live the entire winter in unheated rooms (it was only warm in the secretary's office, where several heaters were on).

While temperature and humidity meant that the viewing sessions and discussions were difficult, the technical aspects of the workshops improved considerably. I was able to buy a projector from NCN project 
funds. At the same time, I managed to negotiate a permit to move the meetings to a renovated classroom in which Italian classes took place in the mornings. There was also a heater for the teacher, which we utilized for the duration of our activities. After difficult negotiations with the administration, our relations have clearly deteriorated. As a result, two compact groups were formed: us - asylum seekers and volunteers ${ }^{20}$ and them - the administration. This was the result of my protests and my strong emphasis on "the duty to treat asylum seekers humanely and the necessity of being respectful in relations with people, especially in difficult situations".

This was witnessed by the participants of the meetings, which immediately changed our relations. I became trustworthy, our conversations and the topics we discussed have changed significantly. During the first months (in order to establish a common viewing experience to prepare for the discussions), each movie was viewed twice. The first viewing included questions, explanations, and introductory discussions after watching the movie. The second viewing was not interrupted. After a few months, I changed the arrangement and we watched the movie once, sporadically pausing it, and after the session, I left the CD in so that the participants could replay the movie as many times as they wanted. This solution also made watching the movie possible for those who, for various reasons, did not attend the meetings. They gathered at a room and turned on the computer - one of many that they received as part of the initiative organized at the University of Warsaw (I brought used computers from Poland, donated specifically for asylum seekers and prepared by an IT specialist $\left.{ }^{21}\right)$.

\footnotetext{
${ }^{20}$ All the aforementioned difficulties were also related to my partner's activities.

${ }^{21}$ I wish to thank an anonymous IT specialist, dr Agnieszka Nowakowska and anonymous persons who participated in this "computers for refugees" action. The IT specialist spent countless hours working for charity, preparing the computers to be used by French and English-speaking people. Computers (over a dozen) contained only legal programs and were in excellent condition. The initiative was organized thanks to dr Agnieszka Nowakowska from the Institute of Sociology of the University of Warsaw - social
} 
The transfer of computers was also seen unfavorably by the administration $^{22}$. The first desktop I brought (to enable the residents a possibility to learn the use of equipment other than phones or the utilization of their existing skills for job-hunting) was withheld by the camp manager on the pretext of observing safety rules. A similar initiative, this time involving portable computers, whose transfer (and possession) was more discreet and not subject to requisition, ended differently.

In spite of the constant problems, quarrels with the administration and unfavorable living conditions, we managed to conduct a year-long series of activities during which, after watching the movies, we could discuss various issues.

\section{Our Cine-Club story}

\section{A. Qu'est ce qu'on a fait a Bon Dieu ${ }^{23}$ - about racism - a common disease}

It was the first movie we watched. The participants have not seen it, but they have heard about it. It is a well-known comedy among the French speakers that tackles ethnic/cultural/religious/racial stereotypes. It is an extended version of a well-known saying: "I am not a racist, but I would not let my daughter marry an African". Since the movie is not popular outside the French-speaking zone, the following section will include a short description of the movie before analyzing its content and the discussions it provoked in the camp.

media proved to be an effective tool in this initiative. This undertaking has shown that there is a great potential in the academic environment and among IT specialists - to provide assistance to those in need. The initiative was anonymous but I informed about some successes of people who received a computer (being accepted to a university, finding a job); everyone used their computers to contact their families and friends in Europe as well as in Africa or Asia.

${ }^{22}$ Such practices are common in the camps. It was not at all the particularity of the fieldwork.

23 French movie - title in English - Serial (Bad) Weddings but the title translated properly is What we did to the Lord for being punished like this - https://www.dailymotion.com/video/xiynvir. 
It tells the story of a pre-retirement couple and their four adult daughters living in Chinon, a peaceful French town $289 \mathrm{~km}$ from Paris. The protagonist of the movie, Claude, has already "married off" his three daughters - the movie is about the fourth wedding.

The family can be described as typically French - with multiple children, belonging to the respected bourgeoisie of the country, living in abundance and in rhythm with provincial life. The father of the girls is a notary, the wife manages their beautiful house, and their daughters are university graduates and work, respectively, as a dentist, attorney, painter and lawyer. The particularity of the family in the context of the town, from which the daughters (livingin Paris) originate, is described by one of the neighbors as the "Benetton family", referring to the famous advertisements of the Benetton company made up of children representing different skin colors. Claude's daughters marry men of different backgrounds. Contrary to what seems exceptional in the provinces, marriages to foreigners or French citizens in the first and second generation belong to more than a quarter of the marriages (there are probably many more PACS partnership contracts). In Verneuil's family, the sons-in-law not only come from countries outside of France, but also from families representing different religions.

The first son-in-law is a French Sephardic J ew trying to succeed as a businessman, the second is an French lawyer of Algerian origin and a Muslim (who does not respect religious restrictions). The third daughter's - the artist's - husband is a banker of Chinese origin. All the hope of older parents to have a French Catholic son-in-law rests with their fourth daughter. When it seems that Verneuil's parents' dream will come true, because the future son-in-law's name is Charles and he is a Catholic, it turns out that he is an actor from Côte d'Ivoire.

When it turned out that the fourth daughter is going to marry an African, the participants were overjoyed - "this is going to be fun" - they said. In line with the stereotype, typically French parents are not happy with their daughter's decision. Even sisters, who can hardly be considered racist, as they created families with people originated from other countries, cultures and religions are trying to dissuade their youngest sister from doing so. I paused the movie after a scene where Charles said that 
they should not be afraid about his family's reaction because Africans are tolerant and open-minded.

Then we discussed the African customs, the hospitality and openness of households. We talked about travelling without money, only with a backpack, and the obligation to feed and offer a place to sleep to travelers - even to strangers. Everything seems easy and simple in Africa - people are friendly and hospitable. "Not like in Europe - here people sleep on the street and nobody lets strangers into their homes..." - added one of the more reserved participants.

Back to the movie. It turned out that Charles encountered the same obstacles as his fiancée. The French notary was as intolerant as Charles' father, an African captain. When the wedding party was to take place, both fathers unanimously declared that they oppose the union because, according to tradition, one should marry a person from their own community. The movie was filled with stereotypical situations, sayings and relations. It turns out that neither the parents, their daughters or their sons-in-law are free from superstitions and reactions fully deserving of the "racist" category. Everyone has their own pool of convictions based on ethnic stereotypes, which are responsible for racist prejudices. Charles summarized the situation as follows, addressing his future wife: "My father is just like yours - the difference is, he's black".

The discussion that followed was lively, especially since some of the scenes were shot in Abidjan, the city from which three of the participants came. In the movie, when Africans were saying a few words in Dioula - some asylum seekers started to laugh while the rest sat in silence; those who knew Dioula were proud that they knew what was happening and were able to translate the phrases used in the movie to us, which allowed us to better understand it; the translation into French was milder what was originally said. The movie brought the whole room to life, and the bursts of laughter interrupted the careful reading of the subtitles (French subtitles require a lot of attention from people who are not used to this type of conversation). The final wedding party scene, with the Coupé-Décalé dance, popular in Côte d'Ivoire, enlivened the participants. Some of them even demonstrated the basic steps. Not everyone knew the dance, but everyone's moods definitely improved. 
We are all the same! That was our first conclusion and that was the motto of our meetings. We are the same, and minor differences merely add color to our bleak reality. In fact, the most difficult thing is to get to know each other - to establish a relationship that enables the deconstruction of a stereotype. We focused on "dissecting" the prejudices in every movie. In order not to limit ourselves to the most obvious examples, we watched two Italian movies Benvenuti al Sud ${ }^{24}$ and Benvenuti al Nord ${ }^{25}$ (based on the French original - Bienvenus chez les Chtis).

The former shows the experiences of a postmaster from Milan, who is sent to work in the south of Naples, and the latter focuses on his employee, a Napoli man, who was transferred to the office in Milan. The plot includes a wide repertoire of stereotypical ideas about the new place to live, but when confronted with reality, the false vision is corrected.

This dilogy discusses the disparity between stereotypes and real situations, which also became the main topic of discussions following the movies. Our conversation highlighted the issue of prejudice, which divides societies. In relation to the movies, which tackled the issue of geographic mobility associated with employment, we also addressed the organization of work and company policies (punctuality, respect for hierarchy, honoring commitments); in addition, we identified the specific characteristics attributed to certain regions - the lazy and always late "southerners" in contrast to the hard-working and punctual "northerners". Because this division concerned Italy, the camp residents accepted the movies as an introduction to the study of the new country.

Subsequent movies stimulated our discussions about the rejection of the "Other", about the difficulty of getting involved in the life of a given group, about the differences in customs. Two movies moved the participants the most. The first one is an American classic from 1967, Guess who's coming to dinner ${ }^{26}$ about one of the first cases of interracial marriages - an African-American and a white American woman. It should not be forgotten that, until the late 60s, some states legally prohibited mixed-raced marriages. The excellent acting highlighted the issues faced by the parents (just like the French movie did) of both families, concerned about the unusual decision of their adult

\footnotetext{
24 https://en.wikipedia.org/wiki/Benvenuti_al_Sud.

25 https://en.wikipedia.org/wiki/Benvenuti_al_Nord.

${ }^{26}$ https://www.imdb.com/title/ttoo61735/.
} 
children, and the following consequences. As this work demonstrates, discrimination is a problem of society, not multi-ethnic or inter-ethnic relationships.

L'Italien (2010) was the second important movie that triggered an emotional discussion ${ }^{27}$. This contemporary French-Italian movie tells the story of a French citizen originated from Algerian immigrant family, who, in order to get ajob (in Nice), pretends to be Italian. Family living in Marseille knows nothing about his ruse, neither do his colleagues. Only one friend who has helped the protagonist forge an ID warned him against the consequences of maintaining the double lie and identity. The situation gets complicated when the French fiancée of the protagonist expresses a desire to meet her future, Italian, in-laws. At the same time, the protagonist's father falls ill and asks his son to follow Ramadan. Muslim fasting is challenging even for a healthy person.

The difficulties encountered by the protagonist in observing religious rules were met with a lively reaction from the audience. Watching this movie during the Ramadan was an additional experience. The vast majority of participants followed the religious principles of the Quran and observing the Ramadan in difficult circumstances was a very close experience to everyone. These difficulties stemmed from the lack of adjustment of the camp's schedule to the religious requirements. Muslims may eat and drink only after sunset, so they fast all day long; unfortunately, during fasting, the distribution of food in the camp does not change, so the diner functions only during the day, at scheduled meal times. In addition, one cannot take food to their room to eat at night to avoid violating religious rules. The protagonist of the movie was in a similar situation as the asylum seekers. He had to hide the fact that he fasted in order not to arise suspicion about his origin (Italians, if they are religious, are usually Catholics).

This movie also raised many questions about the isolationist approach of French society to foreigners - society the asylum seekers usually considered very open. During the discussion on the topic of exclusion, the distance between the participants and myself was further reduced when I shared my experience being an "immigrant woman" in France. Social prejudice on the part of the indigenous (even indignant) population towards newcomers affects everyone, not only people of color. In this respect, my experience of almost twenty years of being a "foreigner" (in a country where I had full

27 https://www.imdb.com/title/tt1612608/. 
rights as a citizen) was akin to crossing a certain border, which at first also contributed to a lack of trust.

Being from Eastern Europe and experiencing the pre-1989 Poland - being a citizen of a country that was difficult to leave (limited possibilities of obtaining a passport) and where getting a visa was not easy (official "invitation" was required) made our conversations much easier. As one of the asylum seekers pointed out: 'You know what it's like when you're not one of them"28.

The conversation following the movie l'Italien introduced Abdelmalek Sayad's concept (Sayad 1999; 2004) - a lie of an emigrant who does not reveal to their family the difficulties and discrimination they are subject to in a new country. This is a hidden truth experienced by every emigrant after reaching their Eden. The discussion triggered by this movie not only changed our relations but thanks to the introduction of sociological concepts, our conversations became very similar to those I had with students of sociology and social sciences. Watching the movies and the subsequent discussions on the issues they presented, the situations they referred to and, above all, the relationships between people they depicted, enabled our group to develop a certain sociological-anthropological ability to dissect cinema.

This made the asylum seekers distance themselves from the issues raised (by generalizing the observed phenomena) and see a different way of perceiving their own situation. Instead of looking at their experience from an individual perspective dominated by difficult personal experience, we have placed it in the trajectory of a group who changed their place of residence and settled in a country dominated by a different culture and language. The life of an immigrant is difficult and an asylum seeker waiting for a permit to live and work in a new country was a long and tumultuous stage for the participants of this study.

\footnotetext{
${ }^{28}$ This affirmation could be understood as "you are like us" but it was not. It indicates only, that I had some elements to the better understanding of an "outsider" situation. I was an "outsider" in France, but in a different context. I was never deprived of the liberty, in jail or in the center of retention; I was never a clandestine immigrant. I was an East-European with a tourist visa, and later a spouse of a French citizen in France. I am also not originated from the "visible" and discriminated immigration and I am not Muslim. All those elements contributed to the fact that I was never in situation that could be close to this of camp inhabitants.
} 
Movies about alienation or acceptance of otherness were not the only ones which grabbed the attention of the participants. In the situation in which they found themselves, far away from their loved ones, movies on the subject of a family were a great way to stimulate the "what it is like at our place" discussions.

\section{B. Kabhie Khushi Kabhie Gham ${ }^{29}$ (2001) - about family strength}

Sometimes Happiness, Sometimes Sorrow - or literally in Hindi - A Bit of Sun, a bit of Rain. A Bollywood movie, starring the greatest stars of Indian cinema. However, it is not a typical movie, despite being kept in a Bollywood convention, as the screenplay and direction are highly artistic and high quality, unlike most blockbusters. This seemingly light-hearted movie deals with the difficult subjects of pedophilia, arranged marriages, adoptions, or marital infidelity. There are also visible class and caste differences, which constitute a strict framework regulating all relationships. Difficult situations are solved by revealing the truth and through strong family ties.

The movie was advertised with a statement: "It's All About Loving Your Parents" which was repeated by the participants on numerous accounts. This movie, as well as other ones tackling the issues of family and obligations towards parents, induced a great share of emotions. I tried not to choose too many of those in order not to deepen the sadness caused by the lack of loved ones. I directed our conversations towards more joyful topics such as weddings and how they are conducted in different cultures. The ceremonies, described in detail, proved to be very interesting for the participants, as it turned out that the general terms: "African wedding", "African rituals" or "African customs" were not applicable. It was not so much the division into national borders, but ethnic, linguistic and tribal categorizations that determined the traditional celebration of a given holiday. It turned out ${ }^{30}$ that neither in Europe nor in Africa or Asia do we have a single continental model for celebrating rituals or a single-family model. The diversity is much greater than any of us had imagined.

\footnotetext{
29 https://en.wikipedia.org/wiki/Kabhi_Khushi_Kabhie_Cham... .

${ }^{30}$ This phrase is a reflection of the group's reaction and not the researcher's statement. It is enough to get acquainted with anthropological works on the subject of conjugal rituals to have no doubts about the complexity of this phenomenon.
} 
The breakthrough stage in our discussions occurred. We began to use systemic comparisons and sociological categories in conversations such as social class, gender roles, perceptions, interactions and trajectories. Since the quality of our group discussions allowed us to address increasingly complex issues, I decided to supplement the range of situations forcing us to redefine the family model or simply to develop an absolute acceptance towards radical differences. For this purpose, I chose the Italian movie Tutta culpa di Freud ${ }^{31}$ (2014).

It tells the story of a father - a psychoanalyst from Rome who raises three daughters on his own - adult but still living with their father. The father, professionally equipped with the art of debating the complexities of relationships, tries to pass on the secrets of "male thinking" to his daughters, stressing the importance of the adequate choice of a partner. Each of them experiences love and their consequences are the subject of the movie.

My choice of the movie was inspired by the portrayal of the first daughter's situation, who has a homosexual relationship with a woman at the beginning, but when abandoned yet again, she decides to have a heterosexual relationship. The topic of homosexuality is a major challenge in many cultures. The situation in Africa is complex and the perception of homosexual relationships in many countries is negative. In Western Europe, same-sex couples have the freedom to live together and marry. A change in attitude can be stimulated by discussions and movies tackling the topic of homosexuality. The Italian comedy Tutta culpa di Freud was an excellent tool in such a discussion. Homosexuality of women and men (Omar Sy's friend in Two is a Family ${ }^{32}$ (2016), a story about a single father raising a daughter, did not provoke any negative reactions. In our conversations, tolerance for all differences became the most respected value, and even the slightest sign of its absence was widely discussed - sometimes without my intervention. Enriched with the ability to discuss increasingly difficult subjects, we decided to change the repertoire together.

Comedies and romantic comedies became part of our watchlist, alongside difficult movies which would fit right in a distinguished movie club's repertoire. Finally, we

\footnotetext{
31 https://www.imdb.com/title/tt3237406/.

32 https://en.wikipedia.org/wiki/Two_Is_a_Family.
} 
arrived at the example discussed below, which I have often used in my classes with sociology students as an effective introduction to the subject of social acceptance of fascism.

\section{Concurrence déloyale 33 (Concorrenza sleale; 2001) - about the banality of fascism}

An Italian-French movie made by the famous director Ettore Scola tells the story of the owners of neighboring clothing stores and their loved ones. The action takes place a dozen or so months before the outbreak of World War II and shows the everyday life of typical, middle-class families, which appear to be similar. The professional status, financial situation, age, family history, education of parents and children are identical. The only thing that divides them is religion - one family is Catholic; the other is J ewish. However, it is not the religion itself that makes the lives of the two families radically different, but the external perception and discrimination of one group. The director masterfully depicts the gradual introduction of discriminatory rules in everyday life (ban on radio, ban on education, boycott of products) and the most interesting issue in the movie is the consent of the neighbors and their reactions to the discrimination.

The participants found the movie very touching. It seemed to me that the last scene, showing the non-Catholic family's relocation to the Ghetto, had a different effect on the participants than on the European students. We had to discuss the bloody history of Europe during the Second World War (it should be mentioned here that in some countries of Africa and Asia, Hitler is not seen as a war criminal and the perception of Nazi Germany is not the same as in Europe).

The story of friendship between two boys - primary school pupils - had a great impact on the participants. It was their relationship that disturbed them the most. Those boys remained friends despite the differences outlined by the context of the discrimination against J ews, while the adult members of the Catholic family succumbed to a dominant tendency to allow harm to their neighbors. After watching this movie, theimage of Europe - an area of high tolerance and "developed civilizations" - changed.

33 https://www.bfi.org.uk/films-tv-people/4ce2b84d26e27. 
Nevertheless, during our discussions, we tried to maintain a micro perspective and look at the great historical changes from the position of ordinary families. Similar reactions of disagreement to divisions and intolerance, as well as a fervent discussion about friendly relations, interpersonal relations, family and clan commitments that go beyond what Europeans think of as hospitality or help, were triggered by Swing ${ }^{34}$, a movie about friendship between a Romani girl living in a camp of travelers and a boy from a local French family learning to play guitar from a Romani musician. A beautiful, emotional story about children and their friendship really touched a group of adult men (20 to 35 years old) who would otherwise be unable to express themselves, believing that the only thing that might interest them was a football match (such opinions were expressed by some of the camp employees). Swing, a poetic work by Tony Gatlif, a Romani director, fascinated the African audience.

It was the result of Gatlif's subtle depiction of friendship and difficult relationships between children belonging to different social groups. The camp's audience found the movies strongly relatable. The complexity and depth of discussions about difficult issues, both European and African "demons" - wars and persecution - made me decide to tackle one of the most difficult subjects (which I often raised in sociology classes with university students) - the death penalty.

\section{The life of David Gale 35 (2003) - on the death penalty and its rationale}

The majority of participants came from countries where the death penalty is legal. Before watching the movie, a discussion about the rightfulness of the prohibition of the death penalty - a rule which applies to all EU member states - took place. As future residents of the EU, the residents of the camp should be acquainted with the legal frameworks, especially those that determine the judicial system.

The movie was based on real events that took place at a university campus in the US. A wrongly accused university professor was put on death row and later executed. Before the final day, the prisoner contacts a journalist and tells her to spread the word 
about his innocence. The tragic event was carefully dissected to ensure that, following the conviction of the alleged murderer, the death penalty was applied, so that later the fragility of the court proceedings could be demonstrated and that a miscarriage of justice with irreversible consequences occurred.

The movie, which is certainly difficult, resulted in a completely different, long conversation unlike those that can be had with European students, for whom the subject matter might seem abstract. Several confessions followed, which concerned close people being convicted, the fear of the death penalty and unjust sentencing. It was not a conversation on intellectual or moral issues, but about real, possible experiences. The contrast between European students and African asylum seekers lies in the fact that the latter were absolutely opposed to the death penalty, while some European students were in favor of extreme solutions and the reintroduction of the death penalty in Europe. The most important value mentioned by the camp residents was life. Some of them avoided certain death and for them, Europe was relatively safe - one of the important elements of this sense of security was the absence of the death penalty. Life is one of the most precious things they have - that was their stance. Despite difficult camp conditions (Wagner, Finkielsztein 2020) all participants discussed their dreams - and what tomorrow may bring. Their visions of the future were also an important subject of our meetings.

\section{E. La vita è una cosa meravigliosa ${ }^{36}(2010)$ - the power of the dream}

An Italian comedy starring famous actors, which depicts the lives of rich doctors from Rome, their family lives and affairs, but also their children's love stories and financial and professional turmoil. A dark-skinned actor plays a supporting role in the movie - a fresh off the boat immigrant working as a home servant for the surgeon - the protagonist. The perfect "emigrant's lie" is in danger of being discovered as the young butler sends pictures of his employer's house to his African relatives. His African family makes a surprise trip to Rome. In order to alleviate this critical situation, the employers

${ }^{36}$ https://www.youtube.com/watch?v=DGnaPhfrGTM. 
(the surgeon and his wife) dress up as servants and pretend to be employed by theyoung African.

The role reversal was highly entertaining for the participants. How is it possible that a white couple serves a black young man? Employers performed their roles so well that the parents returned to Africa convinced of their son's success. The emigrant's lie will remain secret. We watched this fragment several times to translate from Wolof (the language spoken in Senegal ${ }^{37}$ ) into Italian. The participants found a mistake in the original translation and the discussion on language differences led to another discussion on language dynamics in societies without a school system in a given language in place. In Africa, in areas formerly controlled by France and Belgium, children learn to write and read from French textbooks. With the exception of Ethiopia, no country in Africa introduced its own alphabet or operated in an African language. No wonder the asylum seekers from Africa are quite fluent in English or French.

Camp residents are usually multilingual. They know at least two African languages, French (most often) and Italian (in the process of learning). The need for clarification of terms and words, typical of scientific discussions, was a part of every conversation we had. This also showed the great ability to use the language flexibly - based on the belief that there are many ways of expressing the same thing and that every term has numerous interpretations - and consequently, there can be different interpretations of a single event ${ }^{38}$.

The second important plotline of the movie, which involved the medical community, was the main character's decision to change his life (a few years before his retirement, which is understandable) and move to Africa. The decision was enthusiastically applauded by the participants. Africa is the most beautiful place in the world (the included shots were indeed of the most breath-taking African places). This spontaneous reaction made it clear (confirmed by the conversation) that the greatest wish of all participants was to return to Africa permanently. As soon as the situation changes and peace prevails, countries start to prosper, decent medical care or free education is introduced - the asylum seekers will return to Africa. Even if such a statement was merely a non-binding

37 I want to thank Mamadou Bah for the translations.

${ }^{38}$ This is linked to a strong tradition of oral communication (which is more dynamic than written text). 
declaration, it could be treated as truth - which, of course, did not mean that all of them would return to Africa.

Nevertheless, the information about the necessity to settle in Europe (even if only for a while) and the willingness to return to Africa is valuable. One of the most frequently repeated plans - dreams for the future- was to emancipate oneself as quickly as possible, leave the welfare system, find a job, and also to supplement education or simply obtain certain skills in order to be able to work in Africa for the benefit of the people living there. Asylum seeking is only a temporary solution. Education, on the other hand, is one of the most important aims mentioned by the participants in possession of a highschool certificate. Returning to Africa with a university degree is a difficult goal to achieve and maybe that was why the movie about Ron Clark was met with a very enthusiastic reception.

\section{F. The Ron Clark Story 39 (2006) - the power of Education}

The protagonist of this movie is a young teacher who takes up a job in the most difficult area of New York City - Harlem. He is put in charge of preparing a sixth-grade class for their final exam (sixth-grade test) in an unconventional way (rap songs containing mathematical models), but with great commitment. Very difficult and undisciplined students turn out to be children from families where aggression and poverty make it impossible to focus on studying. Their environments and life situations make them destined for failure, thus preventing them from escaping the circle of poverty. The teacher, believing in his students' potential, employs appropriate solutions to create applicable learning conditions and restore their violated dignities. His efforts are fruitful, and the students work daily and achieve unexpectedly high scores - taking first place in the state's ranking.

The story of a deeply neglected class being brought up by Ron Clark provided an optimistic perspective that everything is possible. A change of fate determined by one's "poor" origin and intimidating living conditions is achievable through skillful management of education and great determination. This is a story that the participants

39 https://www.youtube.com/watch?v=fRo5_ngoltM. 
of our meetings believed in. They also noticed changes of their own - in the quality of movie discussions, in the way we analyzed what we discussed, in the way the livened up (even if only for the duration of our meetings), in their interests and in their ability to talk about things that are studied across Europe. I frequently told them that our meetings were partially similar to my academic courses which made the narrative of a better change determined by the improvement of living conditions and educational opportunities plausible. These movies, as well as our discussions about what could be done in a non-hostile environment, served as the beginning of the empowerment process and the belief in a self-driven change.

The story of Ron Clark greatly mobilized the participants to learn Italian. In anticipation of regular classes conducted by a local teacher, they discussed exercises, filled in the missing tasks and repeated some phrases - all while learning Italian from YouTube. I was as proficient in the language as some of the most advanced residents of the camp. This aspect (learning Italian together) was an additional element which reduced the distance between the European researcher and African refugees. However, in two respects, I was not been able to alleviate the perception of the most obvious differences - gender (this issue will be addressed in a separate text) and skin color.

\section{G. Omar Sy and Eddie Murphy - the power of identification}

Two of the most popular Western actors, idols of the participants - Omar Sy, a Frenchman of Senegalese origin, and Eddie Murphy from the US. Both tall and handsome, of different age, but with a similar profile (the American is 17 years older and better known than the Frenchman, both of them are producers, scriptwriters, directors, but also comedians). The characters they play very often have to face various forms of racism and class divisions. Life changes, getting out of a hopeless circle in which a black man inevitably falls into conflict with the law, showing positive potential and finally heroic deeds and/or great successes - these are the movies in which both actors perform excellently. Their works were often included in our sessions. Some of 
them - multiple times (Eddie Murphy: Trading Places ${ }^{40}$, The Distinguished Gentleman ${ }^{41}$, Coming to America ${ }^{42}$; Omar Sy - The Intouchables ${ }^{43}$ ). These actors, with their joyful smiles, are examples of success and proof that anything is possible, similarly to some football players - especially Omar Sy, who is French-speaking and originates from the Peul people. We did not openly discuss the aspect of identification - but it was manifested in what was said: "Father Sy is ALSO Senegalese" or "Sy comes from the same tribe as me".

In these statements, one can feel prideand a regained sense of value- not only white people can be actors - idols... We, too, as Africans, can garner attention. A similar story was told by a group Bengal Muslims who mentioned the life of a Bollywood star, Shah Rukh Khan (a Indian-Muslim), strongly emphasizing the role of his religious involvement and the backstage of a religious-ethnic conflict which took its toll on Bangladesh.

Despite the fact that these actors belong to a different world, through their physical likeness and roles - which show the impact of profound life changes - artists, who are (externally) similar to the asylum seekers have a strong positive impact on self-esteem. For those who remain in the camp for several months, in difficult conditions, condemning them to a depressing slump and completely depriving the asylum seekers of any kind of activity (agency), Omar Sy and Eddie Murphy were a light in the tunnel, which restored hope that being dark-skinned did not mean living in discrimination and being a second-class citizen of Western European/ North American societies.

Their lives and stories they portray were a promise of a better tomorrow.

\section{Double Empowerment}

According to the UNHCR (The United Nations High Commissioner for Refugees), Empowerment is "A process through which women and men in disadvantaged positions increase their access to knowledge,

\footnotetext{
40 https://en.wikipedia.org/wiki/Trading_Places.

${ }^{41} \mathrm{https}$ ://www.imdb.com/title/tto104114/.

${ }^{42}$ https://www.imdb.com/title/ttoog4898/.

43 https://en.wikipedia.org/wiki/The_Intouchables.
} 
resources, and decision-making power, and raise their awareness of participation in their communities, in order to reach a level of control over their own environment" (UNHCR 2001, p. 3).

Using this term regarding the process that was inspired and animated by watching some chosen movies could be seen as an overestimation of the results of such an activity. However, as a conclusion, I will try to show, why I believe that the refugees, who regularly took part in our meetings, started the process of empowerment during this period.

The aforementioned definition includes several elements from which the empowerment is composed. The first is the access to knowledge, the element which each meeting contained, initially in a ludic (leisure) way, slowly reinforced with more information from sociology, geography, demographics, history, anthropology, and political science.

Since the third month of our activities, the participants have become frequent guests in our family home (Wagner 2019); every time we prepared meals together, which constituted active support of both proper nutrition and the social need to share meals and celebrate new relationships, most guests left the house with a book. Our privatelibrary allowed those who were willing to spend some time reading selected novels or books on sociology and history. Reading books outside of institutional context was a strong signal of the socialization process by taking a part of society with them in the form of a book, after a lavish, homely meal ${ }^{44}$.

For asylum seekers from Africa, this situation is attributed to a high social status, because only people from those circles have books at home. This reason alone makes reading books in the camp susceptible to being associated with them. In this situation, we can definitely identify the phenomenon of empowerment. A reader is a respected person. A refugee reader is an independent person. Why? Well, they do

44 Unfortunately, the local library did not lend books to the asylum seekers, even though it was free of charge and not prohibited. All other inhabitants of the town could use the municipal library, with the exception of the asylum seekers who, despite their two years of stay, were not treated as such. 
something that is not required, provided, nor organized by the camp. In that context, on part of every participant who did so, the act of reading came from their own free will and commitment.

Another element of the phenomenon was the increased access to resources, which was a direct result of our meetings. It can certainly be said that the change of mood, the coming out of the slump and numbness, from a state of permanent pessimism, which permeated the majority of people attending the meetings, had a positive impact on their actions, job-hunting skills, and own preparation of the presentation before the committee responsible for determining whether refugee status should be granted. The personal computers organized by the employees and students of the University of Warsaw were of great help in that regard. Knowing how to utilize the Internet to organize their lives after leaving the camp was one of the most important results of our meetings. Preparing an appropriate CV or filling in questionnaires attached to job postings was possible thanks to the regaining of human dignity (as they said - "at last someone treats us like normal people") and believing that change and getting out of the slump was achievable, definitely resulted from the activities and joint discussions on how to change one's fate.

It is difficult to clearly identify the "decision-making power" - another element of empowerment - because the participants failed to establish a camp-inhabitants union, write a petition, or organize a hunger strike. Nevertheless, the decision made by many of the participants (about half of them) to escape from the camp can be classified as decision-making power. Leaving is a difficult decision, as it puts the asylum seekers into the clandestine category - they find themselves in the so-called "Dublin" situation which refers to the Dublin Agreement on asylum seekers - they must remain in camps and apply for status in the EU country of arrival. Those who fled the camp in Italy and still tried to continue the application process may end up being extradited to Italy 
or to the country of origin. Their status will not be granted, and the aforementioned process might be started in a new country in only in exceptional cases (from mid-2019 other solutions are being discussed in order to permit those who fled their camps to file new asylum applications).

It is difficult to say whether and to what extent our activities influenced the decision to escape from the camp. I was not informed about the escape plan and I did not know when it would happen. I only found out later about the whereabouts of those who had fled. This was not a sign of distrust (over time I learned to recognize signals such as tears in the eyes that said goodbye and meant the imminent frappe [a hit - from French - the next stage of the journey]).

Since 2016, the media have been increasingly vocal about the criminalization of the solidarity acts. Not being informed about the escape of my participants served as protection for me and my husband who was also involved in teaching music workshop. From the conversations with the "escapees" that took place a few weeks after their departure (over the phone and directly, at their new places of residence), one can certainly conclude that our discussions made them ready to grab a hold of their lives anew. Entering the illegal world (travel in critical conditions, illegal border crossings, lack of food, drink and accommodation, avoiding the police, being dependent on and in debt with fences) was certainly a difficult context for regaining agency. Nevertheless, the majority has chosen this route instead of having their agency restricted and remaining dependent on the camp.

The element of growth, "their awareness of participation in their communities" can most probably be considered in relation to the situation in which "communities" means "refugees". Following legal changes in European and Italian policies, discussions (on the reception of asylum seekers and the hosts - their ostracism, racism and nationalism) which we have conducted with refugees (especially at 
home, when there was no suspicion of eavesdropping or the presence of those who will report the issues discussed and opinions expressed to the administration) certainly testify to the dynamics of their awareness, even in the case of some people with expert knowledge of the legal, administrative, economic, sociological and political situation of asylum seekers and newly settled immigrants.

Since my regular contacts with the residents of the camp, I have not been able to conduct equally expert discussions on issues related to recent waves of immigration in Europe. This is not only the result of them being insiders. Their opinions are content-related, well-argued and well thought out - expressed from the perspective of a group and not from the perspective of an individual. During these discussions, it is possible to identify the influences of the movies watched and the topics covered.

Finally, after establishing that all the elements were significantly influenced by our meetings, one could argue that the participants reached a level of control over their own environment. Unfortunately, that was not the case. Their empowerment was only partial - consisting of a limited sense of regained agency, but more in the area of thinking or discussion than in the real control over one's own time. Controlling one's own life seemed unreachable. The asylum seekers inhabiting the camps lived in a kind of limbo in which they had no say concerning their future. The culminating moment was to receive the relevant documents to enable them to start a new life in Europe. Making significant decisions in the camp was out of the question. At most, people could decide to humbly wait for a decision or escape. Movie discussions were most likely an important element of decision making in that regard. Each of the participants had to make one during their stay. It was their agency and their empowerment. Strongly limited, circumscribed to the on-off decision whether to stay or to leave - life in clandestinity or survival in the camp. Both situations constitute limbo spaces. 
The secondary result of the workshops was the shadow empowerment. The additional result of refugee's empowerment - kind of the shadow effect or rather the reflection of the sun by the moon and its light that we are capturing in the earth - phenomenon. This was the researcher's empowerment. In the time, when the precariousness of the academics is making this occupation frequently difficult and when especially fieldwork engagement in the difficult settings lays the basis for heavy doubts about the agency of the researcher and the sense of the scientific investigation the new element arise directly from this so depressing fieldwork.

Doing engaged participant research - type of action research — and being bereft of the possibility to act according to the human rights rules and react in a way of protecting the participants, researcher's position could be compared to the physician who is taking care of a patient whose condition declines progressively - this doctor has the tool for doing an efficient diagnosis. He has the treatment in another room and heis only taking measure for observing how badly situation declines but the drugs from the other room are inaccessible. Observed process, which was described in this article, was the main source of my professional satisfaction, which I experienced during the last years. Not the acceptations of my publications or invitations to the conference, but the progressive empowerment of participants.

The aforementioned movies and subsequent discussions were highly impactful. After the waves of laughter triggered by comical situations, which constituted a kind of catharsis in isolation and tension the participants found themselves in, followed peace and hopeful declarations. It will get better someday - we will make it. The African participants of the music workshop sang the French song Il ne faut pas desesperer, and often hummed its melody to me when walking me back to my car. The movies were a new hope for a better tomorrow. Our discussions elaborated our shared emotions - they allowed a verbal 
expression of the most crucial things, not only for the asylum seekers but also for me. They gave us hope, that everything will get better and provided ideas on how to make our reality better. Hopefully, escaping the limbo is possible.

It was our common double empowerment... or... an empowering illusion...

\section{References}

Abou-Zaki H. (2014), Histoire et devenir d'un camp de réfugiés palestiniens [Chatila/Liban], [in:] Un monde de camps, (Ed.) Agier M., Editions La Découverte, Paris

Akthar Z., Lovell A. (2019), Art therapy with refugee children: a qualitative study explored through the lens of art therapists and their experiences, "International J ournal of Art Therapy" No. 24 (3) Archibald T., Wilson A.L. (2011), Rethinking Empowerment: Theories of Power and the Potential for Emancipatory Praxis, Adult Education Research Conference, https:// newprairiepress.org/ aerc/ 2011/papers/3 Agier M. (2016), Borderlands: Towards an Anthropology of the Cosmopolitan Condition, Polity Press, Cambridge Agier M. (2014), Campement, camps de travailleurs, centres de rétension: entre prison, bidonville et ghetto, [in:] Un monde de camps (Eds.) Agier M., Editions La Découverte, Paris

Bartunek J .M., Spreitzer G.M. (2006), The Interdisciplinary Career of a Popular Construct Used in Management: Empowerment in the Late 2oth Century, "J ournal of Management Inquiry|" No. 15 (3) Bauman Z. (2015), Strangers at Our Door, Polity Press, Cambridge Bernardot M. (2007), Les mutations de la figure de camp, [in:] Le Retours de camps? Sangatte, Lampedusa, Guantanamo..., (Eds.) L'huilier G., Valluy J ., \& Le Cour Grandmaison O., Autrement, Paris 
Bernardot M. (2014), Une situation coloniale sans fin. Le Centre d'Acceuil des Français d'Indochine (1956-2006) - Sainte Livrade France, [in:] Un monde de camps, (Ed.) Agier M., Editions La Découverte, Paris

Brown C., Schale C., Nilsson J. (2010), Vietnamese Immigrant and Refugee Women's Mental Health: An Examination of Age of Arrival, Length of Stay, Income, and English Language Proficiency, "J ournal of Multicultural Counseling and Development" No. 38

Centre Primo Levi (2018), La souffrance psychique des exilés. Une urgence de santé publique, https:// www.primolevi.org/wp-content / themes/ primo-levi/ La\%20souffrance\%20psychique\%20des\%20ex il\%C3\%A9s_Rapport\%20pages.pdf [06.11.2019]

Cernovsky Z. (1988), Refugees' Repetitive Nightmares - Czechoslovak Refugees in Switzerland between 1970-72, "Journal of Clinical Psychology" No. 44 (5)

Crepet A., Rita F., Reid A., Van den Boogaard W., Deiana P., Quaranta G., Barbieri A., Bongiorno F., Di Carlo S. (2017), Mental health and trauma in asylum seekers landing in Sicily in 2015: a descriptive study of neglected invisible wounds, "Conflict and Health" No. 11, https:// doi.org/ 10.1186/s13031-017-0103-3

Chandrashekhar Oka R. (2014), Coping with the Refugee Wait: The Role of Consumption, Normalcy, and Dignity in Refugee Lives at Kakuma Refugee Camp, Kenya, "American Anthropologist" No. 116 (1)

Denaro Ch. (2012), La crisi del 'Modello Lampedusa'. Studio di caso sulle politiche di gestione dei flussi migratori provenienti dal Nord Africa, MA thesis, Sapienza University, https:// www.academia.edu/ 4299302/La_crisi_del_Modello_Lampedusa [02.12.2019]

Deveaux M. (1994), Feminism and Empowerment: A Critical Reading of Foucault, "Feminist Studies" No. 20(2)

Duneier M. (1999), Sidewalk, Farrar, Straus and Giroux, New York 
Edogué-Ntang J.-L. (2014), L'empreinte de la souillure dans les campement près de la frontière, [in:] Un monde de camps, (Ed.) Agier M., Editions La Découverte, Paris

Foucault M. (1980), Truth and Power, [in:] Idem, Power/Knowledge: Selected Interviews and Other Writings, 1972-1977, Pantheon Books, New York

Freire P. (1970), Pedagogy of the oppressed, Continuum, New York Gatti F. (2007), Bilal. Viaggiare, lavorare, morire da clandestine, Rizzoli, Milan

Godin M., Hansen K., Lounasmaa A., SquireC., Zaman T. (2017), Voices from the 'Jungle'. Stories from the Calais Refugee Camp, Pluto Press, London

Goffman E. (1961), Asylums: Essays on the social situation of mental patients and other inmates, Anchor Books, Garden City

Halilovich H. (2013), Ethical Approaches in Research with Refugee and Asylum Seekers Using Participatory Action Research', [in:] Values and Vulnerabilities: The Ethics of Research with Refugees and Asylum Seekers, (Eds.) Block K., Riggs E., Haslam N., Australian Academic Press, Toowong

Harper D. (1982), Good Company, University of Chicago Press, Chicago Héran F. (2019), Comment l'Europe accueille - ou non - les demandeurs d'asile depuis 2015, Institut Convergences Migrations, http:/ / icmigrations.fr/ 2018/ 12/ 04/ defacto-2-003/ [02.12.2019]

Hughes E.C. (1945), Dilemmas and Contradictions of Status, "The American J ournal of Sociology" No. 50 (5)

Iwińska K (2008), „Theory of Agency” w socjologii europejskiej, "Rocznik Lubuski" Vol. 34, Pt. 2

J ansen B.J . (2014), Le camp dans l'économie de la ville de la région et du monde" Kakuma (Kenya), [in:] Un monde de camps, (Ed.) Agier M., Editions La Découverte, Paris

Kaba A. (2019), Esclave de Milices, Fayard,Paris 
Kouamé (2018), Revenu des ténèbres: Le récit boulversant d’un jeune migrant, $\mathrm{XO}$ éditions, Paris

Lecadet C. (2014), Le deu de la révolte. Le camps comme foyer politique” Agamé - Bénin, [in:] Un monde de camps, (Ed.) Agier M., Editions La Découverte, Paris

Lexico (2019), Empoverment, https://www.lexico.com/ en/ definition/ empowerment [02.12.2019]

Liebow E. (1995), Tell Them Who I Am: Lives of Homeless Women, Penguin Press, London

Macmillan Dictionary (2019), Empower, https:// www.macmillandic tionary.com/ dictionary/ british/ empower [02.12.2019]

Comparative Perspectives on Social Movements. Political Opportunities, Mobilizing Structures, and Cultural Framings (1996), (Eds.) McAdam D., McCarthy J., Zald M., Cambridge University Press, Cambridge

Nosè M., Ballette F., Bighelli I., Turrini G., Purgato M., Tol W., Priebe S., Barbui C. (2017), Psychosocial interventions for post-traumatic stress disorder in refugees and asylum seekers resettled in highincome countries: Systematic review and meta-analysis, "PLoS ONE” No. 12 (2), https:// doi.org/ 10.1371/journal.pone.0171030

Omizzolo M. (2016), La Quinta Mafia, Radici Future, Roma

Omizzolo M., Fanizza F. (2019), Caporalato: An Authentic Agromafia, Mimesis International, Italy

Orland N. (2017), La main de Fatima. Le K-mer voyageur, Les editions Sydney Laurent, Paris

Pitzer A. (2017), One Long Night. A Global History of Concentration Camps, Little, Brown and Company, New York, Boston, London

Powdermaker H. (1967), Stranger and Friend: The Way of an Anthropologist, W.W. Norton \& Co Inc., New York

Sayad A. (1999), La double absence. Des illusions de l'émigré aux souffrances de l'immigré, Seuil, col. „Liber”, Paris 
Sayad A. (2004), The Suffering of the Immigrant, Polity Press, Cambridge

Scheibelhofer E. (2019), Conceptualising the social positioning of refugees reflections on socio-institutional contexts and agency with a focus on work, "Identities" No. 26 (3)

Solomon B.B. (1976), Black empowerment: Social work in oppressed communities, Columbia University Press, New York

Tassin L. (2014), Un laboratoire de la rétention en Europe, [in:] Un monde de camps, (Ed.) Agier M., Editions La Découverte, Paris

UNHCR (2014), Speaking for Ourselves: Hearing Refugee Voices, $A$ Journey Towards Empowerment, Geneva, https:// www.refworld. org/ docid/537afd9e4.html [02.12.2019]

UNHCR (2001), A Practical Guide to Empowerment, Geneva, https:// www.unhcr.org/ uk/ protection/ women/3bbc24532/practic al-guide-empowerment.html

Wagner I. (2019), Impossible Agape: A Fieldwork in the World of Refugees and the Limits to the Researcher's Role, "Sociologia” No. 1 Wagner I., Finkielsztein M. (2020) [forthcoming] 'Strategic Boredom' - Inspection of Boredom in the Refugee Camps: Working with Blumerian Sensitising Concepts [In the process of publication] Zimmerman M.A. (2000), Empowerment Theory, [in:] Handbook of Community Psychology, (Eds.) Rappaport J ., Seidman E., Springer, Boston 